\title{
APROXIMACIÓN COGNITIVA AL TEXTO
}

\author{
Guijarro Morales, José Luis
}

Universidad de Cádiz, Departamento de Filología Francesa e Inglesa, Facultad de Filosofia y Letras, C/ Bartolomé Llompart, s/n, 11003 Cádiz, Tfno.: 956-245013, Fax: 956.220444

(Recibido Marzo 1997; aceptado Junio 1997)

BIBLID [1133-682X (1997-1998) 5-6; 173-209.]

\section{Resumen}

Las investigaciones sobre el texto se centran en sus aspectos intrínsecos ( $s u$ forma, su contenido, etc.), olvidando que estos aspectos "intrinsecos" no aparecen hasta que algún ser humano se enfrenta con ese objeto-texto de una determinada manera. El cognitivismo intenta anclar los procesos de interpretación en entidades que existen antes de que la interpretación se realice; es decir, indaga en el funcionamiento de la mente cuando se enfrenta con estímulos distales (como el objeto-texto) y proximales (como el camino interpretativo personal) En este trabajo se presentan algunas consecuencias de la aplicación de dicho enfoque merecedoras, quizá, de ser tenidas en cuenta en futuras investıgaciones sobre el texto que pretendan alcanzar el nuvel de adecuación explicativa.

Palabras clave: cognitivismo, texto, interpretación, nıveles de adecuación.

Este trabajo ha sido posible gracias a la beca de movilidad que me fue concedidapor el M.E.C. para trabajar en el Centre de la Recherche en Épistemologie Appliquée (École Plytechnique), dependiente del Centre National de la Recherche Scientifique francés, en Paris durante los meses octubre y noviembre de 1995. Agradezco al director del grupo de investigación "Raisonnement", Dan Sperber, asi como a sus colaboradores, Francesco Cara, Roberto Casati y Gloria Origgi sus comentarios e interés por mi trabajo Igualmente agradezcoa François Récanati, linguista de] centro, sus indicaciones valiosisimas sobre algunos aspectos de este artículo.

Pragmalingristica, 5-6, 1997-1998, 173-209. 


\begin{abstract}
Text research centres around its inirinsic aspects (its form, its content, etc.), apparently unaware that they do not exist until a human being interacts with the object-text in a certann way. Cognitrism tries to analyze interpretation processes by studyng entities that precede that interpretation: that is to say, the functioning of the human mind when processing distal stımuli (as the object-text) and proximal stimuli (as the interpretative way a certain individual may take). This paper tries to show some of the consequences that could be drawn fruitfully to reach explanatory adequacy in these matters.
\end{abstract}

Key words: cognutivism, text, interpretation, levels of adequacy.

\title{
Résumé
}

Les travaux sur le texte sembient accorder une grande importance à ses aspects internes (sa forme, son contenu, etc ), oubliant, que ces qualités-ci ne se manifestent qu'aprés son interaction avec un individu. Or, le cognitivisme prétend analyser les processus d'unterpretation à partir, justement, des données preéxistentes à cette interaction. Notre étude s'occupe du fonctıonnement de l'esprit humain quand il traite l'ınformatıon quı lui parvient des stimuli extérieurs (comme le texte) et intérieurs (comme le chemin interprétatıf personnel). Nous essayons, donc, d'en tırer des consequences qui pouraient constıtuer une explication scientifique du phenoméne.

Mots-cles: Cognıtivisme, texte, intérpretation, nıveaux d'adéquation.

\section{Sumario}

1. Niveles de pensamiento. 2. Algunos ejemplos que ilustran el funcionamiento de estos subsistemas. 3 Posibilidades de conseguir un pensamiento científico en nuestro campo de estudıo. 4. Metodología cientifica básıca. $5 \mathrm{El}$ problema del "TEXTO" visto a la luz de esta nueva metodologia científica. 6. Bosquejo de análisis.

\section{Niveles de pensamiento}

Voy a empezar recurriendo a una idea que ya he expuesto en otro trabajo ${ }^{2}$ y que podríamos denominar "historia ficción del desarrollo mental de nuestra especie". Según esta idea, el ser humano está equipado para re-presentar $r^{3}$ aspectos del mundo externo

\section{Gujarro (1994).}

${ }^{3}$ Es decir, para volver a presentar en su sistema de almacenamiento de información algo que le permita reaccionar aceptablemente para su supervivencia (Cfr, Guijarro, 1994). Más ajustadamente,

Pragmalunguistica, 5-6, 1997-1998, 173-209 
e interno con arreglo a un programa especie-especifico. Este mecanismo de creación de representaciones es demasiado complejo para desmenuzarlo aquí. Distinguiremos, por ahora, y de manera muy esquemática ${ }^{4}$, tres subsistemas en el mismo:

$\left.1^{\circ}\right)$ Denominaremos primario, al subsistema que utiliza los objetos abarcables por los sentidos como datos propios. La conversión de los objetos abarcables de la realidad exterior en datos (o representaciones) se realiza en procesos automáticos y semiautomáticos que están inscritos en el programa de la especie. Algunos investigadores llaman a estos procesos modulares'.

Pero hay algo más que una conversión de objetos en datos; el sistema actúa de tal manera sobre estos datos que (automática, o semi-automáticamente), produce bechos, que son nuevas representaciones en donde se relacionan estos datos en cadenas de causaefecto. Tanto los datos, como los hechos, sirven para realizar inferencias. Por ejemplo: "Esta planta que comí (causa) me curó la tos (efecto positivo), o me dió dolores de tripa (efecto negativo), por lo que si (inferencia) quiero quitarme la tos / o no quiero que me duela la tripa ( $2^{2}$ premisa), tendré que tomármela / tendré que evitarla (conclusión).

El valor de supervivencia de este sistema primario de representaciones está avalado por el proceso de evolución de la especie. Los individuos, por tanto, elaboran estas representaciones y realizan operaciones sobre ellas, de manera espontánea y sin que quepan dudas sobre su eficacia. Las cosas son así, y esto basta para sobrevivir -como lo ha demostrado nuestra evolución.

representar es abstraer datos de la realidad (percibida o, Incluso, imventada) y tenerlos dispuestos en alguna parte de la memoria para su recuperación (casi) inmediata, si hacen falta. Representar, como percibir, es una función biológica que consigue la adaptación del organismo humano a su entorno. Esta función biológica se materializa en microestados cerebrales (las representaciones) o, lo que es lo mismo, estructuras físicas de neuronas de las que todavia sabemos muy poco, aunque fenomenológicamente, estas representaciones se presentan ante nuestra conciencia como un estado psicológico con determinadas estructuras de tipo mental. Para comprender más claramente los problemas que esta multıplicidad de planos de observación acartea, Cfr De Vega (1984), Rivière (1986) y Papineau (1987), entre otros muchos.

'Esta historia ficción está basada en ıdeas muy similares del antropólogo, R. Horton, aunque e'las define de distinta manera y las emplea para caracterizar aspectos de las culturas africanas. Cfr.: Horton (1967, 1982). Otro antropólogo cognitivista, Boyer (1990), critica esta concepción de Horton de manera bastante acertada. Sin embargo, he adoptado la descripción del primero porque ilustra de manera gráfica algunas razones de las que me impulsan a intentar una explicación materialista.

Cfr Fodor (1983) ofrece una explicación pormenorizada de estos tipos de procesadores. 
$2^{\circ}$ ) El paso al subsistema secundario puede ser descrito así: de los hechos representados se elaboran nuevos datos, y de éstos, nuevos hechos y nuevos datos, de una manera imparable. El mecanismo de representaciones humano adquiere la posibilidad de producir datos a partir de objetos no abarcables por sus sentidos. Se mantiene la tendencia de inferir causas de efectos y viceversa, ampliándose extraordinariamente el poder de predicción del futuro, lo cual mejora ostensiblemente su posibilidad de supervivencia como especie. Además, el ser humano encuentra la manera de utilizar su sistema inferencial para hacer públicas sus representaciones privadas, con lo que las empieza a compartir, adquiriendo así un potencial aún mayor de representaciones. Como he dicho más arriba, (a) las que crea a través de lo que perciben sus sentidos, (b) las que él mismo crea y (c) las que le "comunican" sus semejantes ${ }^{6}$.

El funcionamiento de este tipo de sistema no está, por tanto, avalado por la historia de la especie, ya que filogenéticamente acaba de surgir, como quien dice, antes de ayer. Es más, puede resultar muy caótico y poco recomendable para la especie. En efecto, cada individuo es capaz de imaginar las causas más dispares para los efectos representados a su modo y manera, sin obtener ninguna garantía de su validez como instrumento de supervivencia.

Se requiere, entonces, un mecanismo que controle este posible caos representacional, encauzándolo, para lograr los fines de la continuación de la especie. El mecanismo natural es limitar autoritariamente la superproducción indiscriminada de representacioncs. Es decir, la decisión sobre las representaciones útiles se traslada del individuo al grupo.

En otras palabras, la garantía del buen funcionamiento del sistema vendrá dada por el mayor número de personas que lo compartan, en el presente y a lo largo de generaciones pasadas. Es lo que se llama el peso de la tradición: se considera que el mecanismo individual productor de representaciones es, en principio, sospechoso, cuando no totalmente nocivo. Si resulta manifiestamente contrario al tipo de representaciones avaladas por el grupo presente y los que le precedieron, habrá que destruirlo para

Ejemplo de este sistema de representaciones: "Hay un mundo en el que vivimos (objeto no abarcable, producto de los datos que hemos ido sacando a través de nuestros sentidos y de lo que otros nos han contado) que, como todas las cosas que están en dicho mundo, ha debido de tener un principio, un orıgen". Sabemos, además, que "todo efecto es producto de una causa, luego el origen del mundo ha de tener una causa, una causa inconmensurable que es dificil de imaginar, pero fácil de nombrar en una representación pública: Dios".

Pragmalinguística, 5-6, 1997-1998, 173-209. 
asegurar la supervivencia del grupo ${ }^{7}$.

$3^{\circ}$ ) Hace escasamente medio segundo en la historia de nuestra evolución, el sistema de representaciones humano ha adquirido una nueva función, la que realiza su sistema terciario. Dicho subsistema puede haber surgido ante el choque de representaciones más o menos tradicionalmente avaladas, con lo que:

( $\left.1^{\circ}\right)$ Se empieza a cuestionar la falta de potencial predictivo de muchas de las representaciones grupalmente valoradas como ciertas y que, no obstante, entran en conflicto entre sí. En efecto, no hay manera de decidir cuál elegir basándonos solamente en "el peso de las tradiciones" respectivas ya que, como es obvio, carecemos de medios realmente objetivos para medir claramente dicho peso.

$\left(2^{\circ}\right)$ Se intenta volver a confiar en el dispositivo primario de representaciones que faculta al individuo a enfrentarse bastante acertadamente con su entomo de realidades materiales.

Sin embargo, es imposible dar marcha atrás en la evolución y olvidar el mecanismo de creación de representaciones tan potente que ya ha adquirido la especie humana con su sistema secundario y su facultad de hacer públicas sus representaciones mediante el lenguaje. Surge, por ello, este nuevo subsistema representacional cuyas características son muy claras, porque ni son innatas, como las del mecanismo primario, ni son implícitas, como las del secundario, sino que son, a su vez, representaciones conscientes de lo que ha de ser un mecanismo corrector de representaciones demasiado potentes y validador de inferencias descontroladas.

Este mecanismo, por tanto, limita las posibles explosiones imaginativas del sistema secundario con una sencilla transposición de las reglas inferenciales del mecanismo primario. Se requiere que las cadenas causales que se establezcan sean materiales. Esto tiene como consecuencia que muchos de los datos imaginados a lo

Pero esto hay que matizarlo: todo grupo acepta representaciones individuales de personas que considera debidamente preparadas (según la tradición) Los gurus, chamanes, etc. no ponen en peligro la supervivencia del grupo, sıno que, o interpretan las representaciones públicas, o crean otras nuevas con suficientes garantías de su valor tradicional. (Muy interesante en este aspecto "tradicional" de la novedad representacional públicamente compartida es el trabajo de Boyer (1990). El problema surge cuando uno de estos chamanes entra en conflicto con la mayoria de los demás chamanes y es considerado transgresor de la tradición; en este caso, puede, o ser destruido, o innaugurar una nueva tradición.

Pragmalinguística, 5-6, 1997-1998, 173-209. 
largo de generaciones y generaciones (p.ej. conceptos como almas, dioses, vidas ultraterrenas, etc.) vayan poco a poco desapareciendo del campo de este dispositivo representacional. En cambio, cada vez es más cierto que los únicos objetos que se procesan en este dispositivo son aquellos cuya sustancia es "material" (se rige por leyes físicas y/o químicas).

A partir de ahora, en vez de las denominaciones de dispositivos representacionales primario, secundario y terciario, a menudo utilizaré pensamiento como sinónimo de "dispositivo representacional", y llamaré de sentido común al "primario", tradicional al "secundario" y cientifico al "terciario"s".

\section{Algunos ejemplos que ilustran el funcionamiento de estos subsistemas}

Toda/o niña/o que nace en el mundo parece que tiene una capacidad innata para comprender su entorno físico semi-automáticamente, sin mucha enseñanza especifica. Muy pronto distingue lo vivo de lo que no lo es, lo sólido de lo líquido, etc. Adquiere, digamos, una biologia o una física básicas que funcionan bastante bien. Ningún(a) niño/a se enfada porque una mesa no le hace caso, ni se empeña en empujar un aro con una guita, por ejemplo.

Pero todo infante debe de ser "educado" en las representaciones admitidas por la sociedad en donde ha nacido. Cada una/o hemos pasado por ello y, por tanto, recordaremos algunos de los preceptos incomprensibles que hubo que aceptar, aunque costara mucho lograrlo. En nuestra cultura, también se nos empezó a enseñar (a las/los privilegiadas/os) que se podía pensar "científicamente" en algunos campos.

Lo curioso del caso es que algunos de estos campos, hoy considerados científicos, no lo fueron hasta muy recientemente. Pongamos un ejemplo muy evidente: se trata de nuestras representaciones sobre lo que perceptivamente se nos aparece como objetos y eventos no localizados en nuestra tierra: fenómenos atmosféricos, objetos celestes, etc. Durante mucho tiempo, tales representaciones fueron simplemente avaladas por la tradición reinante, sin más. Quiere esto decir que los "objetos" celestes (los planetas, las estrellas, así como, analógicamente, nuestra buena "madre" Tierra) y los fenómenos

"Téngase en cuenta que la aparıción del pensamiento científicono es todavla claramenteun "avance" especie-específico; los grupos que lo han adoptado parecen, en el estado actual del mundo, imponerse sobre los que todavía no lo han hecho. Sin embargo, y como ya indiqué antes, hay todavla muchas incógnitas sobre si este tipo de pensamiento levará o no a la humanidad a un nivel más elevado, o a su entera desaparición, junto con la del entomo en el que existimos. En este trabajo no entro en este tipo de valoraciones, ya que carezco de datos sobre el problema.

Pragmalinguístıca, 5-6, 1997-1998, 173-209. 
atmosféricos (tormentas, vientos, auroras, etc.) fueron considerados o encarnaciones de dioses o productos de las actividades divinas. Hoy en día, existen todavía representaciones de este tipo, algunas sumamente elaboradas en un entramado organizado que se denomina "astrología" y que se trata de desligar de lo que son verdaderas teorías científicas sobre dichos objetos y fenómenos ("climatología", "astronomia", etc.), tanto por los que creen en la veracidad de tales representaciones astrológicas, como, evidentemente, por los que no las consideran digna de ningún crédito.

Ignoro casi todo sobre estos temas, pero estoy seguro de que, básicamente, muchas de las representaciones que conforman la astrología se pueden rastrear en el principio de los tiempos en que nos consta que el ser humano las representó. Intuyo, también, que existen algunas maneras novedosas de representar y de comunicar lo que en realidad son representaciones antiguas o, ¿por qué no? innatamente determinadas ${ }^{9}$, con lo que los astrólogos podrían argumentar que su campo de estudio ha evolucionado modernamente.

A pesar de ello, sin embargo, suponiendo que existieran congresos y simposiums de astrólogos, nadie se asombraría si un docto especialista en esta materia citara a un sacerdote egipcio de la primera dinastía como aval de una de sus ideas. Es decir, se trata de un pensamiento típicamente secundario, tal y como lo hemos definido arriba.

En cambio, desde que Newton tuvo la idea de utilizar un lenguaje matemático para aplicar los hallazgos de la fisica terrenal a lo que ocurre en el cielo, la astronomía se ha separado cada vez más de las intuiciones avaladas por las generaciones pasadas e, incluso, de las representaciones humanamente concebibles de manera directa. Se ha hecho pensamiento terciario. Muy pocos físicos o astrónomos actuales citan a Tycho Brae, a Galileo, a Kepler, o al mismo Newton en favor de sus teorías. Las representaciones físicas y astronómicas de nuestros científicos no surgen principalmente, ni de la observación simple de los fenómenos perceptibles, ni de las representaciones culturales, sino más bien de la aplicación estricta de una metodología materialista expresada matemáticamente. Por ello es posible encontrarnos con conceptos contraintuitivos como antimateria, agujero negro, expansión o contracción galáctica, quanta, supercuerda, etc. que ningún físico o astrónomo de la antigivedad pudo siquiera

${ }^{9}$ Así, por ejeplo, Dennett (1878) nos explica que el ser humano está innatamente determinado para atribuir intencionalidad a sistemas complejos (organismos vivos, personas y, a veces, fenómenos naturales que no entiende bien -de ahi que los "dioses" de las religiones y mitologías tengan esa cualidad que, por su complejidad, le atribuímos a determinados seres vivos y, sobre todo a los seres humanos. Por ello, es cierta la idea de que en realıdad el ser humano crea a los dioses a su imagen y semejanza).

Pragmalinguisfica, S-6, 1997-1998, 173-209 
imaginar (como, de hecho, no podemos hacerlo nosotros) ${ }^{10}$.

Tenemos que hacer una pausa aclarativa aquí: todos los seres humanos, incluidos los de mente más científica, están determinados genéticamente para utilizar de la misma manera su sentido común; igualmente, todos los seres humanos, incluidos, de nuevo, los de mente más científica, están determinados culturalmente por su pensamiento tradicional. No hay ninguna escapatoria al funcionamiento primario; la hay en el caso del funcionamiento secundario, pero resulta muy difícil $\mathrm{y}$, a menudo, traumática. En cambio, el pensamiento científico, como ya dije anteriormente, no está determinado ni genética ni culturalmente; el individuo que lo adopta lo hará de manera consciente, mediante un cierto entrenamiento que permita sobreponerse a las representaciones automáticas del sentido común". No obstante, muchas de las representaciones que elabore una mente entrenada para el pensamiento cientifico, incluso sobre aspectos del campo de su "investigación", seguirán siendo primarias y/o secundarias.

\section{Posibilidades de conseguir un pensamiento científico en nuestro campo de estudio}

Para la gran mayoría de los que nos dedicamos a investigar distintos aspectos relacionados con la comunicación de los seres humanos (como pueden ser, su mente, su lengua, su arte, etc.) no existe más metodología investigadora que la que tiene características parecidas a las que hemos postulado para la astrología. Es decir, sólo podemos pensar sobre estos temas con nuestro sistema secundario, el creado y avalado por la tradición cultural. Así, no resulta extraño citar como autoridades para corroborar nuestras ideas actuales, por ejemplo, a Platón y Aristóteles o, más cercanamente, a Freud y Jung, Saussure y Bloomfield, Burkhart y Croce, etc. O, dicho en pocas palabras: parece que no ha habido nunca un cambio de paradigma. como el que describe Kuhn (1970), para las revoluciones científicas.

\footnotetext{
${ }^{10}$ Ante este estado de cosas, muchas personas creen que estamos volviendo a los conceptos religiosos y que, en realidad, los físicos actuales interpretan los misterios de la naturaleza de manera equivalente a como lo hacían (lo hacen) los sacerdotes y los gurus. Sin embargo, si se comprende el proceso mental empleado en ambos casos, se percibe una diferencia absimal en los dos tipos de interpretaciones.

"Esto sucede incluso con las propias reglas de inferencia; no es igual la "logica" del sentido común que la "logica" científica. Sobre las caracteristicas de la lógica del sentido común, Cfr Sperber, Cara \& Girotto (1994).
}

Pragmalinguística, 5-6, 1997-1998, 173-209 
No es de extrañar que para muchos científicos esté claro que las únicas ciencias verdaderas son las emparentadas con la física o la química. Las pretensiones (de algunos de los que nos dedicamos a cuestiones filosóficas, psicológicas, lingüísticas o artísticas) por encontrar relaciones materiales de causa-efecto entre distintas representaciones abstractas sin aparente soporte real es absolutamente ridicula por lo imposible de tal objetivo. En esto, dichos científicos están básicamente de acuerdo con los llamados humanistas que afirman que los objetos propios del humanismo (la creatividad ${ }^{12}$, lo ético, el ego, las oraciones de relativo, la belleza, etc.) se distinguen substancialmente de los objetos de la física, la química, la biologia, etc. Esta concepción -la de que hay dos tipos de entidades de las que ocuparse intelectualmente- está basada en el pensamiento tradicional, ya que admite como válido lo que las distintas generaciones que han elaborado nuestra cultura han establecido, tanto en sus representaciones teóricas, como en la práctica.

Hay, evidentemente, razones para explicar el por qué de esta dicotomía en nuestra representación de las substancias: las substancias materiales, aunque podamos representárnoslas, se hallan fuera de nosotros; los experimentos que podamos hacer con y sobre ellas tienen efectos materiales externos, además de los que tengan en nuestras representaciones. Por eso, con una metodología científica apropiada, podremos salirnos de nuestras percepciones y posteriores representaciones intuitivas sobre ellas y encontrar representaciones que emergen objetivamente al aplicar dicha metodología.

En cambio, las substancias no materiales, incluso las perceptibles, son siempre representaciones internas. Unas son representaciones privadas, Jas otras públicas; pero no existe nada fuera de nosotros que podamos claramente apuntar como soporte de nuestras representaciones. Mejor dicho, utilizamos una serie de objetos que, convertidos en datos, son solamente indicios de que nuestras representaciones representan algo para nosotros. Si seguimos asi, deberemos comprender que a lo más que podemos aspirar, en el mundo de la ciencia, es a que se nos considere unos charlatanes de ingenio, muy parecidos a los astrólogos. Y como hoy en día el prestigio de la ciencia es evidente, ¿quién puede asombrarse de que la sociedad y sus instituciones políticas nos abandonen a nuestra suerte, $\sin$ (casi) ayudas o alicientes que animen a investigar estas cuestiones? ¡Bastante hacen que no nos envían al paro forzoso de un plumazo!

Las preguntas relevantes en este punto son: ¿Cómo pasar de las concepciones

\footnotetext{
- Mucha gente se alegra de la supuesta inaccesibilidad de la creatividad para la ciencia (...) [Se] supone que la creatividad, que es la gloria suprema de la humanidad, no puede mancharse con los tentáculos reduccionistas de la explicación cientifica. En la dificultad de comprenderla está precisamente su esplendor Estos puntos de vista son tomados por muchos como verdades literales. Pero nunca se analizan críticamente. No son teorías, sino mitos. (Boden, 1990*4).
}

Pragmalinguistica, 5-6, 1997-1998, 173-209. 
ingeniosas de filósofos, psicólogos, lingüistas, críticos de arte, etc. a teorías cientificas sobre estos temas? ¿Se puede intentar un cambio de paradigma, pasando de la "astrologia" (pensamiento secundario) a la "astronomia" (pensamiento terciario), en nuestro campo de estudio? En pocas palabras, ¿es posible una teoría mecánica de la mente?

La respuesta (esperanzadora para muchos) es que sí. Que si se puede. Que, de hecho, el cambio de paradigma ha sucedido ya hace algún tiempo, cuando el matemático británico Alan Turing, como un Newton revivido, encontró la manera de crear una simplísima máquina abstracta cuyo funcionamiento simulaba operaciones mentales en pasos materialmente discretos. Máquina que fue posteriormente implementada mecánicamente por Von Neumann y que es la base de la moderna informática ${ }^{13}$. Por fin, los filósofos. psicólogos, lingüistas y estudiosos de las otras manifestaciones mentales del ser humano tienen a su disposición una metodología científica que, como la de las ciencias físicas, es apta para hacer emerger representaciones cada vez más distintas de nuestras intuiciones subjetivas. Estas nuevas representaciones emergentes serán objetivas $\mathrm{y}$, por tanto, las únicas que podremos aceptar científicamente como base de nuestra investigación.

Mi insistencia en la importancia de las representaciones objetivas emergentes que cada vez se distinguirán más de nuestras intuiciones subjetivas sobre estos temas puede hacer pensar que lo que estoy propugnando es algo totalmente apartado de la realidad. Ello sería una falsa impresión que me apresuro a disipar.

Al igual que sucede con la astronomía o la física, por ejemplo, la ciencia surge para dar cuenta de los fenómenos que, en principio, se perciben y se procesan por los sistemas humanos de captación y de tratamiento de información. Para los entendidos, la física de Newton se plantea estas cuestiones sin separarse mucho de la fenomenologia cognitiva humana. Sin embargo, en su afán por lograr explicaciones más ajustadas y universales, la física actual, la quántica, la de las supercuerdas, etc., ahonda en los problemas de una manera tal que la fenomenología se queda lejos y, como dije antes, las explicaciones y representaciones son cada vez menos cognitivamente intuitivas, ganando en cambio mucha potencia predictiva y, por ello, explicativa.

\footnotetext{
"La obra de Turing puede considerarse el primer estudio de la actividad cognitiva, en que ésta se abstraía en principio, por completo tanto de sus fundamentos biológicos como de sus implicaciones fenomenológicas ... representa la emergencia de un nuevo nivel de análisis, independiente del fisico pero de espíritu mecanicista. hace posible una ciencia de la estructura y la función divorciada de la sustancia material (...). Dado que habla el lenguaje de las estructuras mentales y los procesos intemos, puede dar respuesta a cuestiones planteadas tradicionalmente por los psicólogos (Pylyshyn, 1986: 68, citado por Clark (1990: 10) y traducido al castellano por Rivière (1991: 56).
}

Pragmalmguistica, 5-6, 1997-1998, 173-209. 


\section{Metodología cientifica básica}

Cualquier investigador que pretenda aplicar a su trabajo el sistema terciario de pensamiento deberá tener en cuenta la siguiente batería de requisitos:

(A) El nivel de OBSERVACIÓN: Ha de tener claro qué fenómeno está realmente observando. Cuanto menos claros sean los límites entre lo que constituye el entorno del problema y el problema mismo, menos científica será la teoría en este primer nivel.

(B) El nivel de DESCRIPCIÓN: Una vez que se sabe qué observar, hay que poder describirlo adecuadamente. Lo difícil es ponerse de acuerdo sobre qué es "adecuado". Parece que la descripción más adecuada será aquella que deje menos aspectos del problema a cargo de la intuición; entre otras cosas, porque las intuiciones son representaciones individuales y nunca podemos estar seguros de que los demás sepan exactamente lo que son nuestras intuiciones. Al compartir nuestras ideas, hemos de intentar que nuestras intuiciones individuales sean compartidas. Por eso tratamos de hacerlas públicas de la manera más clara posible para que los demás sepan a qué atenerse sobre nuestra descripción. Si dos teorías describen un fenómeno, la más explícita (en el sentido técnico del término explicito ${ }^{14}$ ) será la más adecuada científicamente.

(C) El nivel de la EXPLICACIÓN: Una teoría científica ha de ser capaz de aportar explicaciones "reales" a problemas determinados. Y aunque no toda la comunidad científica está de acuerdo, es un hecho indiscutible que, para un sector científico (el más representativo, tradicionalmente, de lo que es la ciencia pura y dura), las únicas explicaciones reales son las causales, es decir, las que se dan en la naturaleza material.

El nivel de la explicación requiere una clarificación, porque si no, al tratar de analizar fenómenos que, en apariencia, no son totalmente físicos (como, por ejemplo, los fenómenos mentales, que son los que aquí me van a interesar), podríamos quedarnos, o en aspectos muy superficiales de los problemas, o absolutamente bloqueados en nuestro

' La explicitud de un enunciado viene dada por su significado decodificado y por la serie de inferencias directamente relacionadas con los elementos de dicho enunciado ( $C f r$ Sperber \& Wilson, 1986). Como la explicitud nunca es absoluta y siempre hay posibilidad de no llegar a compartir las mismas representaciones individuales, la ciencia modema trata de construir enunciados formalizados para sus explicaciones públıcas en este nivel Sin embargo, no es absolutamente necesario formalizar toda explicación científica, aunque la posibilidad de conseguirlo en algún momento sırva a veces de guía para el científico.

Pragmalinguistica, 5-6, 1997-1998, 173-209. 
esfuerzo por lograr una teoría científica. Para evitarlo, conviene subdividir el nivel explicativo, a su vez, en tres subniveles ${ }^{15}$ :

(A) EL SUBNIVEL ABSTRACTO (COMPUTACIONAL): Sería el nivel superior, en donde se analizaría el problema mental como una tarea de procesamiento de la información.

(B) EL SUBNIVEL ALGORÍTMICO: Donde se analizarían los procesos reales por medio de los cuales se realizaría la tarea del procesamiento de la información (descrita en el primer nivel).

(C) EL SUBNIVEL FísICO: Es el nivel más bajo, puesto que se refiere a la maquinaria neural y trata de determinar cómo ésta ejecuta los procesos del nivel algorítmico (descritos en el segundo subnivel), con lo que cumple su tarea de procesamiento de la información (que se analiza en el primer subnivel).

\section{El problema del "TEXTO" visto a la luz de esta nueva metodología científica}

¿Existe realmente un "problema" del texto? Quizá sea solamente derivado de una confusión terminológica. Para comprender lo que pretendo hacer notar tendré que recurrir a lo que planteé en otro trabajo (en prensa) sobre ciertos conceptos relevantes al respecto:

Podriamos convenir en que mensaje seria cualquier conjunto de representaciones privadas que se consiga hacer público mediante un proceso comunicativo ${ }^{16}$. Quedarian

\footnotetext{
Cfr. Marr (1982).
}

Evito conscientemente la imagen metafórica, fuertemente anclada en nuestra manera de pensar sobre la comunıcación humana, de hablar de mensaje como "traspaso" (o incluso "intercambı") de información. Un traspaso (o intercambio) de información es otra cosa: por ej., traspasamos (o intercambiamos) información si entregamos unos papeles, o un disquette de ordenador. Pero no estoy traspasando (o intercambiando) ninguna información ahora, ya que la que haya en mi mente sigue estando en ella; y la que yo intento hacer pública por medio de estas tiras de palabras escritas, tampoco se va a ninguna parte (aunque alguien las leyera o leyese). Simplemente, estoy tratando de que alguien recree en su mente ideas equivalentes a las que me parece que tengo y que creo estar organizando con dicho fin. Otra cosa es, naturalmente, que alguien "traspase" estos papeles a otra persona con el fin de que también los lea.

Pragmalingtiistica, 5-6, 1997-1998, 173-209. 
excluídas del concepto, por tanto, las representaciones que surgen a partir de experiencias no comunicativas (como, p.ej., las que se crean a partir de los sensores humanos, $o$ las que se fabriquen mentalmente, sin que se intenten compartir con nadie más ${ }^{17}$ ).

Llamaré lenguaje al sistema de potencial extralingüístico acompañado, muy a menudo, del potencial lingǘstico que tiene el ser humano a su disposición para comunicar mensajes.

Obsérvese que el lenguaje, así entendido, puede ser únicamente no-verbal ${ }^{1 /}$ (p.ej., el lenguaje de los gestos), o, conjuntamente, no-verbal y verbal (p.ej., el que empleamos en las conversaciones). En cambio, por mi definición, no existe un lenguaje únicamente verbal. Para esta parte exclusivamente verbal reservo el término de lengua.

Con esta diferencia (lenguaje/lengua) pretendo apuntar a dos maneras de organizar las ideas para hacerlas públicas:

Por una parte, la actualización de ideas más o menos equivalentes en otras mentes se logra con comportamientos que las manifiesten de alguna manera (p.ej., si señalo la luna con el dedo, indico que estoy pensando en algo relacionado con ella; si muestro mis bolsillos vacios, manifiesto mi faita de pecunio, etc.).

Por otra, la actualización de estas equivalencias puede lograrse mediante la organización de estructuras de la lengua que hayamos aprendido (es decir, bien sea el idioma materno u otro posteriormente adquirido).

Hay que hacer una salvedad. Ni la manera comportamental, ni la manera lingüística, pueden prescindir de utilizar la capacidad inferencial de las mentes humanas para lograr la comunicación de mensajes. Por ello, mostrar la luna puede interpretarse de diversas maneras que hay que deducir de premisas contextuales, igual que hay que deducir los mensajes a partir de las frases lingüísticas y del contexto en donde se emplean. Lo que ocurre es que, en el lenguaje no-verbal, todo son deducciones, mientras que en el lenguaje verbal, podemos simplificar mucho el cuadro si consideramos las operaciones de inferencia de dar sentido a sonidos y/o signos como operaciones de (de)codificación, basadas en una serie de reglas estructurales que suponemos manifiestas

\footnotetext{
${ }^{17}$ Es decir, solamente en la comunicación (que es el proceso intencional de compartir información) se producen mensajes. La información que nosotros podamos sacar de un cielo nuboso ("que posiblemente va a llover"), del ruido extraño que produce un coche ("que el coche tiene una averia"), o del humo ("que allí hay fuego"), etc. no nos permite decir que el cielo, el coche o el humo nos hayan comunicado ningún mensaje; solamente es lícito decir que nos permiten derivar una información de ellos. En cambıo, sı queremos compartır esa información con otras personas, entonces sí que crearemos (y trataremos de que otros compartan) "mensajes" .

" Por ello es posible que hablemos del lenguaje animal sin forzar demasiado el térmmo.
} 
en todos los que empleen un idioma determinado. En pocas palabras: en el lenguaje verbal, hay un proceso que, fenomenológicamente al menos, se nos aparece como cualitativamente distinto al de la inferencia a base de premisas no codificadas ${ }^{19}$.

Podemos. seguidamente, convenir en que (acto de) discurso es la actualización del lenguaje humano siempre que se emplee tanto el potencial extralingüistico como, y sobre todo, el lingüístico. (Parece contraintuitivo representarse un discurso sin elementos lingüísticos; pero como, por el momento, carezco de término para designar la actualización de una secuencia de lenguaje no verbal, consideraré posible hablar de discurso no verbal ${ }^{20}$ ). Está claro, por tanto, que el mensaje está organizado en un acto de discurso.

Nos queda, por tanto, referirnos a lo que sea el texto. La definición más neutra del mismo es la de Brown y Yule (1983), que lo definen como "el registro verbal de un discurso"; registro que puede realizarse en la mente de un ser humano (en su memoria), o en cualquier otro lugar (superficie, configuración magnética o electrónica, etc.).

Entonces, ¿dónde está el problema?

Permítaseme que recurra a un ejemplo didáctico que podria haber ocurrido a lo largo de mi carrera de profesor. Supongamos que presento las siguientes tiras de palabras

" Asombra pensar que esto no se habia planteado hasta que el filósofo norteamericano, Paul Grice, lo hizo a mediados de este siglo. Asi, Mehrabian (1972) y otros estudiosos no consideran el lenguaje no verbal como constituido por operaciones básıcamente inferenciales, sino que lo tratan como si fuera una verdadera lengua no verbal, es decir, con un funcionamiento (de)codificador, más o menos implícito ( $₫$ ?), lo cual es la única dıferencia (,!) que encuentran con el lenguaje verbal (si sigo su teminología). Se trata de una opinıón enmarcada en el paradigma semıotzante, instaurado por De Saussure en Europa y por Pierce y Morris en América, que ha demostrado ser de difícil erradicación. Ver, por ejemplo, la obra mucho más reciente de Poyatos (1994), por poner un ejemplo cercano pero, de ninguna manera, único. En cambio, a la sombra de Grice, mucha pragmática modema se basa en esa distinción. Así, por ejemplo, lo tenemos muy claramente expuesto en Sperber \& Wilson (1986). Sin embargo, pragmáticos de fuste, a pesar de reconocer el valor de la inferencia en la comunicación humana, no son capaces de desligarse totalmente de la pesada carga de la semiótica y pretenden codificar algunas operaciones inferenciales, con lo que pierden el sentido de la intución griceana. Como veremos, además, 51 no somos capaces de distinguir claramente entre ambos procesos, se pueden crear confusiones insalyables a la hora del análisis como se verá al final de este trabajo.

${ }^{20}$ Coincido, en esto al menos, con Castilla del Pino (1988), cuando dice que "Todo acto de conducta...compone un discurso", aunque no sé si suscribo totalmente su ılustración siguiente, cuando afirma que "Discurso es tambićn el acto mismo de escribir. de encender la luz, de caminar" (p.184). Para $m$, quizá sea posible considerar el acto de escribir como discurso, puesto que hay una intención comunicativa; encender la luz y camınar no me parecen actos de discurso en el contexto en el que me estoy tratando de mover.

Pragmalinguistica, 5-6, 1997-1998, 173-209 
a mis estudiantes:

\section{AMANTES}

No pude creerlo hasta que les descubri. Muchos me lo habian advertido. En aquel momento ella, asustada, dejó de maullar, pero él, que no se daba cuenta de que les estaba mirando, todavia siguió ladrando un rato.

(Luis Mateo Diez: Piezas sueltas)

$\mathrm{Y}$ que, seguidamente, solicito que comenten el texto. Sigamos suponiendo que me entregan los siguientes comentarios:

1. Es un texto precioso, porque está en un tarjetón de pergamino de Prusia y los trazos son los que hizo el grán caligrafo de la $5^{\circ}$ Dinastía. Stink-Fu-Tsé.

2. Es un texto muy fácil: (1 $\left.{ }^{\circ}\right)$ Porque tiene la letra muy grande. $\left(2^{\circ}\right)$ Porque es muy cortito (y se puede volver a releer sin problemas). (Etc., etc.)

3. El efecto central de este relato consiste en el cambio de rumbo de la historia. Empieza indicando (pero no diciendo explicitamente) que se trata de unos amantes sorprendidos por el marido, que es el que nos relata el suceso, y acaba proponiendo que lo que el narrador no "podía creerse" es que eran gata y perro los amantes. (Etc., etc)

4. Este texto es un relato, pues se le puede aplicar la conocida afirmación de Tzvetan Todorov: "Todo relato es movimiento entre dos equilibrios semejantes, pero no idénticos" (Etc., etc.)

Supongo que, en general, se consideraria que un(a) estudiante que hiciera los comentarios 1. ó 2. no habría entendido lo que era un comentario sobre un TEXTO. En cambio, los comentarios que empezaran con los párrafos 3. y 4. podrían, si mantenían la interesante tónica inicial, llegar ser aceptables. 
Podríamos aumentar el número de comentarios inaceptables y el de los aceptables, pero con este botón de muestra me basta para mostrar que realmente hay un problema aquí. Se trata del empleo de la palabra TEXTO y de su relación con la palabra COMENTARIO.

El problema, según podemos apreciar, es doble:

$1^{\circ}$ ) Tratar TEXTO (un fenómeno que existe físicamente en el mundo y que puede ser percibido como tal objeto) como sinónimo de DISCURSO (que es, como vimos arriba, la creación de mensajes más o menos equivalentes por medio del lenguaje).

$2^{\circ}$ ) No tener muy clara la idea de lo que sea realmente un COMENTARIO. En efecto, al pedir un comentario sobre un texto podemos estar pensando en:

(A) Que se reflexione sobre el (único) mensaje que "contiene", sin preocuparse de los pasos discursivos dados para conseguir un mensaje (no totalmente determinado). Es decir, consideramos (inconscientemente ${ }^{21}$ y, por tanto, sin ni siquiera una sombra de duda) que la objetividad física de lo que estamos "observando" se traslada del texto al plano (no analizado) de un solo mensaje que está en el texto, o, mejor dicho, que es el texto mismo ${ }^{22}$.

(B) Explicitar los caminos por los que el receptor ha recreado el discurso a partir del texto y, sólo posteriormente, reflexionar sobre los efectos del mensaje conseguido. En otras palabras, ser conscientes de que el fenómeno que estamos observando no es físicamente equiparable al "objeto" texto, sino que se trata de una construcción mental que se ha ido elaborando paso a paso a partir de una serie determinada de estímulos que habría que descubrir científicamente.

\footnotetext{
Algunos dirian que es realmente de senido común verlo de esta manera. Pero este sentido común, me temo que no es el pensamiento primario, sino producto de largos años de tradición y, por tanto, secundario.

Asi queda claro por qué los comentarios 1 y 2 son valorados negatıvamente y, en cambio, los comentarios 3 y 4 se ven aceptables. En puridad, habria que haber definido el plano en que estábamos observando el objeto "texto". Como acabo de decir en la nota anterior, esta definición se da por asimilada por el pensamiento secundario que es el que estamos preparados para instaurar en nuestras/os estudiantes $y$, por ello, es normal que no valoremos las representaciones de texto que estén más cerca de las propjedades físicas del texto que, quizá, fueran las primarias y, por tanto, de verdadero sentido común.
}

Pragmalinguistica, 5-6, 1997-1998, 173-209. 
Ante esto, se imponen dos reflexiones:

( $\left.l^{2}\right)$ Demasiadas veces en nuestros actos comunicativos, presuponemos que la información que intentamos compartir carece de ambigüedades; lo cual puede llevar a incómodos malentendidos. Esto se deriva de la concepción reinante sobre la comunicación humana que considera que los malentendidos son fruto de un mal funcionamiento comunicativo. Poco a poco, sin embargo, y desde diversas perspectivas, se va abriendo paso la idea de que la comunicación humana es bástcamente indeterminada y que se necesitan muchos esfuerzos para lograr una información mutuamente manifiesta ${ }^{23}$.

(2) La que hace Fodor (1985): Todo el mundo sabe que algo está mal. (...) Lo que está mal es que no hacemos las distinciones suficientes. Si hiciéramos las distinciones necesarias seriamos tan felices como reyes. Y todo el mundo sabe que los reyes son muy felices.

Precisamente, hasta aquí he tratado de mostrar que, quizá, no somos siempre capaces de hacer todas las distinciones requeridas.

El impasse está en la manera de enfocar los problemas de las representaciones creadas por el ser humano privadamente y hechas públicas de alguna manera para compartirlas con los demás. Desde que el ser humano se ocupa de estas representaciones (llámense "filosofia", "literatura", "historia", "ciencia" etc.), su reflexión se ha centrado normalmente en las representaciones, digamos, terminadas y que se consideran uniformemente compartidas; muy raramente en el proceso por el que se adquieren tales representaciones. Por ello, es fácil caer en el error de representarse un MENSAJE como algo que está completo en un TEXTO (que se ve como un objeto del mundo real) y no como un DISCURSO (que es una actividad natural, no obviamente accesible a la introspección. Cuesta creer que, hasta hace poco tiempo, las cuestiones de la comunicación humana no se han comenzado a estudiar de manera objetiva 0 , por decirlo llanamente, de manera científica. Para ello, ha habido que separarse cada vez más de las representaciones mentales que (a) surgen espontáneamente en nuestras mentes (por el funcionamiento de las operaciones perceptivas o de las comunicativas) y que, (b) tradicionalmente, han sido elaboradas en construcciones teóricas nunca analizadas, ni en

\footnotetext{
${ }^{23}$ Cfr, Sperber \& Wilson (1986); Gibbs (1994), etc. Piénsese lo que les cuesta a los legisladores crear leyes claras y exactas. Los juristas saben desde siempre lo que hasta ahora había sido pasado por alto por los teóricos de la comunicación y de las lenguas humanas.
}

Pragmalinguistica, 5-6, 1997-1998, 173-209 
su manera de originarse, ni en su manera de compartirse ${ }^{24}$.

Un campo afín en donde este tipo de planteamiento también es evidente es en la pintura. Sólo recientemente empiezan los teóricos a darse cuenta del problema. Así, hablando del objeto físico, el cuadro, Baxandall (1985) dice:

(..) lo que ofrecemos en una descripción [de un cuadro] es una representación de la reflexión sobre un cuadro, más que una representación de un cuadro. Decir que nosotros "explicamos un cuadro como filtrado a través de su descripción" puede considerarse convenientemente como otra forma de decir que explicamos, en primer lugar, las reflexiones que hemos tenido sobre el cuadro $y$, sólo en segundo lugar, el cuadro propiamente dicho.(...) La mayoría de las mejores cosas que podemos pensar o decir sobre los cuadros se sitúan en una relación ligeramente periférica respecto al cuadro propiamente dicho ${ }^{25}$

Termina esta reflexión refiriéndose a los términos que se emplean en este tipo de comentarios descriptivos: (1) Los que hacen referencia DIRECTA al efecto del cuadro sobre el observador (p.ej., conmovedor). (2) Los que hacen dicha referencia de manera INDIRECTA, recurriendo a palabras metafóricas que comparan dichos efectos con otros que podríamos tener (p.ej., resonancia de color). (3) Los que hacen referencia al efecto del cuadro sobre el observador de manera que le permiten INFERENCIAR las causas que impulsaron al artista a actuar de la manera que lo hizo (p.ej., mano segura, paleta limitada, excitados borrones, etc. ${ }^{26}$.

Resumamos lo dicho hasta aquí: el cuadro es una representación pública que puede verse y apreciarse por muchas personas, cada una de las cuales tendrá su propia representación privada del mismo. $\mathrm{Y}$, como dice Baxandall, lo que cada una de esas personas hará al describir el cuadro es hacer públicas sus representaciones privadas (o, en sus palabras, el efecto) que el cuadro le ha producido.

¿Ocurre lo mismo con el texto? Sí y no:

\footnotetext{
${ }^{24}$ Lo cual es más grave, como demuestra nuestra decisión de "suspender" cuando creemos que los estudiantes comparten los mismos conceptos que nosotros (p.ej., qué es texto y, por tanto, cómo hay que comentarlo) y en realidad no es asi (como sucede en el caso de los comentaristas de 1 y 2 ).

-- Págs. 19 y 20 de la traducción española en Blume (1988).

fbrdem.
}

Pragmalinguística, 5-6, 1997-1998, 173-209. 
Para empezar, un cuadro puede ser descrito teniendo en cuenta sus caracteristicas físicas, tal como aparece en índices y catálogos (medidas, forma del marco, tipo de pintura empleada y de superficie pintada, etc., junto con fecha y nombre del pintor).

La descripción de un texto como objeto físico es raramente pertinente, aunque no parece que a primera vista haya ninguna razón para ello, como acabamos de indicar.

Para seguir, cuadros y textos puede describirse ${ }^{27}$ como ejemplos de género (retrato, paisaje, naturaleza muerta, etc. o novela, drama, poesía, etc.). Los rasgos que determinan lo que sea género son evidentemente representaciones públicas en una determinada cultura que, por hoy, no vamos a tratar de explicitar. De todas maneras, conviene recordar de nuevo (¡una vez más!) que, tanto en el cuadro, como en el texto, esos rasgos se refieren a lo que las formas (pintadas o escritas) efectúan sobre ios receptores que las interpretan, aunque no lo hagan directamente, sino a través de esa criba de representaciones socialmente compartidas que son los géneros.

Para terminar, aunque es muy posible que muchos, influídos por la "semiótica"2t consideren que hay que decodificar ciertos mensajes a partir de las formas pintadas por el artista (formas que son parte integrante del cuadro), está muy claro que, sin haber visto nunca pintura japonesa, es posible interpretar un cuadro de Mizoguchi de alguna manera y hasta valorarlo; lo mismo que ocurre con los cuadros abstractos modernos que, curiosamente, tienden a ser valorados negativamente por las personas... ¿que no saben decodificarlos? ${ }^{29}$.

En cambio, es indudable que si no somos capaces de decodificar un texto, porque esté escrito en una lengua desconocida, no podremos interpretarlo ni, por supuesto, valorarlo.

Quizá, en vez de describirse tendria que haber empleado la palabra adscriburse, con lo que esta aparente equivalencia entre texto y cuadro a la hora de "describirlos" no sería tal. En fin, dejémoslo como está por ahora.

¿ Cuyos postulados, no lo olvidemos, son hipótesis y no hechos reales, como ahora parece que se consideran. Por lo que cuestionarlos no es ningún disparate imperdonable, sino un sano esfuerzo por comprender mejor la adquisıcıón de información que consiguen los seres humanos a través de diversas fuentes y mediante procedimientos diversos.

- Si no lo supıeran decodıficar, esas personas que valoran negatıvamente lo que interpretan en un cuadro abstracto, no se atreverían a hacerlo de manera tan contundente. Nunca hemos oído a nadie que no hable chino criticar un poema de Li-Tai-Po escrito en ese idioma. Si lo hiciera, todos lo consideraríamos un disparate. En cambio aceptamos (más o menos) naturalmente que alguien diga que Tapies no pinta más que estupideces.

Pragmalinguística, 5-6, 1997-1998, 173-209. 
En otras palabras: la información que sacamos de las formas (al interpretarlas) que alguien ha puesto en esos dos objetos, cuadro y texto, no se consigue de la misma manera, aunque la semiótica no las distinga y las agrupe bajo el mismo nombre de información (de)codificada.

Parece un trabalenguas; vamos a ponerlo en esquema:

Una descripción de un cuadro es:

$1^{\circ}$ Una representación (que es pública porque está creada por un discurso: el de la "descripción")

DE

$2^{\circ}$ Una representación (que es privada porque la constituyen los efectos que el individuo estima que le ha producido lo que ha interpretado al percibir el cuadro).

\section{DE}

$3^{\circ}$ Una representación (que es pública porque para eso la pintó su creador.

\section{DE}

$4^{\circ}$ Una representación (que es privada del pintor que la ha intentado plasmar). Veamos:

¿Podemos aplicar este esquema al comentario de un texto? Repito: sí y no.

Un comentario (de texto) es:

$1^{\circ}$ Una representación (que es pública porque está creada por un discurso: el del comentario)

\section{DE}

$2^{\circ}$ Una representación (que es privada porque la constituyen los efectos que el individuo estima que le ha producido lo que ha interpretado al percibir y leer el texto)

DE

$3^{\circ}$ Una representación (que es pública porque, para eso, la escribió el autor) 


\section{DE}

$4^{\circ}$ Una representación (que es privada del autor que la ha intentado plasmar).

He repetido las mismas palabras en ambos esquemas para mostrar por qué SÍ se puede aplicar este esquema a ambos objetos. Pero, como se ve, hay dos pequeñas diferencias (es decir, NO se puede aplicar en su totalidad):

a) En la primera representación (la pública del comentarista), los efectos son causados de la misma manera en el caso del cuadro como en el del texto literario. Ambas son discursos del mismo tipo: "descriptivo".

b) En la segunda representación (la privada del receptor/comentarista), los efectos no los causa sólo, ni principalmente, la percepción, como en el cuadro ${ }^{30}$; sino, y por este orden, $1^{\circ}$ la percepción de las letras ordenadas de una determinada manera que, si es capaz de descifrar, $2^{\circ}$ le lleva a su lectura y, solamente de ahí, a su posterior interpretación ${ }^{31}$.

\footnotetext{
II- Ante esto cabe seffalar que la percepción también debe "aprenderse" (como pasa con el códıgo), ya que una persona que no esté acostumbrada a percibir cuadros o fotografias o, incluso, películas, no verá nada parecido a lo que nosotros vemos "naturalmente". Como dice Barley (1983), en su libro El antropólogo inocente: "[Los dowayos]... no identificaban las imágenes de las fotografias. En Occidente solemos olvidar que hay que acostumbrarse a ver fotograflas. Nosotros tenemos contacto con ellas desde la más tiema infancia de modo que no nos es dificil identıficar rostros u objetos captados desde cualquier ángulo, bajo una luz distinta o incluso con lentes deformantes. Los dowayos no tienen tradición en el arte visual: sus creaciones se limitan a franjas de dibujos geométricos (pg.123)". La explıcación de esta aparente similitud en el aprendizaje respectivo se debe a que, al comparar ambos procesos, lo estamos haciendo en un nivel consciente (aunque nos refiramos a aprendizajes inconscientes), con categorías fenomenológicamente claras (el código es una de ellas). Posiblemente, habria que tratar de describir los procesos en un nivel infra-cognitivo, como pienso hacer más adelante.
}

3: Algo semejante a esto es lo que propone Vega (1984) ante la lectura de los mapas

(...) el mapa es algo más que una estructura gráfica sobre el papel. Sólo adqiere su pleno sentido y funcionalidad si alguien to lee e interpreta correctamente, desvelando las correspondencias existentes entre los símbolos y la realidad ( $\mathrm{vg}$. "línea roja igual a autopista"). Dicho de otro modo, el mapa cartográfico implica una dualidad estructuraproceso. La primera es fisica y se puede describir por procedimientos métricos, pero el segundo componente, de caracter inferencial e interpretativo, es esencialemnte

Pragmalinguistica, 5-6, 1997-1998, 173-209. 
(c) En la tercera representación (pública) del esquema, dicho carácter se debe a dos tipos de acciones distintas: pintar y escribir. Sé que es obvio, pero a veces lo obvio no se ve y se hacen metáforas deformantes como la de la (de)codificación.

(d) En la cuarta representación (privada del pintor/autor) el problema está en su naturaleza. En principio, se trata de una representación que el pintor/autor tiene en su mente y que es capaz de plasmar en imágenes o en palabras para hacerla pública. Pero, muchas veces, en la creación de este tipo, la única representación privada es la de CREAR una representación pública que no existe como tal en la mente. sino que se va plasmando a medida que se ejecuta.

Parece muy claro que la única representación pública objetiva posible (al menos, en el nivel de la descripción) es la que se realiza sobre un objeto evidente para el científico: su propia representación privada de la representación pública que es el cuadro o el texto. Una descripción (representación pública) que pretenda analizar otra representación pública (el cuadro o el texto) se equivoca de objeto $\mathrm{y}$, por ello no puede ser apropiada. El objeto que hace pública la representación privada del autor/pintor no

cognitivo (la negrita es mia). (Pg.248)

Es súmamente interesante, en este sentido, el estudio de los textos escritos organizados en figuras que realiza Gross (1997). Según esta autora, lo que la mente realiza es un movimiento continuo entre la actividad de la lectura y la que necesitamos para captar la imagen. Este movimiento es necesarıo pue sólo podemos percibir de una u otra manera en un determinado momento, de la misma manera que lo hacemos cuando interpretamos figuras ambiguas. Es interesante su conclusión:

Learning to read means learning to stop considering letters and words as images. Pattern poems remind us of the visual aspect of writing that we have come to suppress. They not only restore the iconic dimension of signs and of reading but also place it in a productively contradictory, eyeopening relationship with our acquired, automatic reading practice. By defamiliarizing not only signs but also the process through which they are decoded, by calling on our resources and asking us to respond to different modes of signification. they liberate both texts and readers.

Por últırno, Scarry (1995) afinna que así como todas las demás artes utilizan de alguna manera los mismos sentidos que tenemos para enfrentamos con la realidad, el arte escrito carece de esta propiedad, por lo que los esfuerzos de los autores se dirigen a conseguir representacrones que, aún siendo únicamente imaginadas y, por lo tanto, menos nítidas que las que realmente percibimos, consigan un mayor grado de viveza que las representaciones que imaginamos voluntariamente sin instrucciones previas. 
se crea para ser descrito, sino con otro fin. En esto se halla la base de la confusión de las ciencias humanas.

Dicho esto, veamos qué caracteriza la escritura y la lectura que las distingue de la pintura y su percepción. En la pintura y su percepción están en marcha procesos "intrinsecos" de creación de representaciones. Las representaciones creadas e interpretadas al modo intrínseco son las imágenes. En la escritura y la lectura, los procesos son "extrínsecos". Las representaciones creadas e interpretadas al modo extrínseco son las proposiciones ${ }^{32}$.

Esto hay que explicarlo:

Al hablar de procesos que crean representaciones de manera intrinseca me refiero a aquellos que funcionan preservando inherentemente la estructura de lo representado (es decir, producen representaciones que son analógicas), por lo que sus elementos de relación no son explícitos.

Los que crean representaciones extrínsecas, al no ser, en cierto sentido, isomórficas con lo representado, necesitan emplear elementos relacionadores explícitos ${ }^{33}$ para presentar las relaciones existentes (Cfr. Rivière, 1992).

En pocas palabras, la equivalencia entre la realidad y las representaciones no necesita, en este nivel de análisis, de ningún código que las relacione cuando son analógicas. Mientras que es indispensable dicho elemento explícito, cuando no lo son. Pintar es realizar imágenes en cierto sentido isomórficas con aspectos de la realidad ${ }^{34}$. Escribir, en cambio, requiere utilizar elementos explícitos que no aparecen en la realidad y que, por tanto, hay que (de)codificar para poder interpretar.

Como acabamos de ver, la manera de observar las representaciones ha de dar un vuelco total. En vez de poner las representaciones públicas en el medio y hacer que nuestras representaciones privadas (nuestros "comentarios", nuestras "descripciones" o "reflexiones") giren alrededor de ellas, tendremos ahora que observar nuestras

\footnotetext{
No entramos en la posibilidad y manera de pasar de uno a otro tipo de representación que también habrá que estudiar en su momento.

33 Por elemento explicitose entiende aquí cualquier producto de la actividad humana de simbolizar (de poner en relación algo con otra cosa) que se haya hecho pública. Por eso, los signos "implícitos" del lenguaje no verbal de algunos semióticos que antes mencioné son una verdadera contradiccıón terminológica que habría que evitar.

Esto no se debe de tomar como una descripción de que la pintura es una representación isomórfica de las cosas que percibimos; puede también ser una descripción realmente analógica de un proceso creador que se ha plasmado en una serie de formas más o menos abstractas ( $C f r$. . Puelles, comunicación personal)
}

Pragmalinguística, 5-6, 1997-1998, 173-209 
representaciones privadas y determinar cómo cada una de ellas se forma y contribuye a la representaciones públicas existentes. Si no lo es, se parece mucho al giro copernicano en la observación del firmamento. Y, lo que es más grave, todavía: cuando algunas de las representaciones públicas se materializan de alguna manera no podemos olvidar que dicha materialización es el resultado parcial de un proceso mental y comportamental, pero, de ninguna forma pueden tomarse por la representación misma (que siempre será mental).

En definitiva. el texto, tal y como muchos lo entienden todavía, no existe para el científico; sólo para el lector. No deberíamos, por tanto, pretender que el texto de una poesia, una novela, o una noticia pueda ser analizado cientificamente.

En efecto, el mensaje sólo se puede estudiar científicamente enfrentándose con la actividad mental que cada uno realizamos al interpretar un texto: con el proceso discursivo. El texto, a lo más, puede servir como guía para comprender ese proceso.

Fijémosnos en las implicaciones de lo que estoy planteando:

(1) Si seguimos estudiando el texto como los efectos del mensaje que cada uno sacamos de él al interpretarlo, nuestras reflexiones no serán objetivas y, de hecho, diferentes personas o, incluso, la misma persona en distintas épocas de su historia personal, pueden analizar cosas diversas en cada caso. No existe la objetividad necesaria para lograr el primer nivel de cientificidad, porque no estamos analizando en realidad el texto.

(2) Si somos conscientes del primer problema que nos enfrentamos al analizar científicamente un texto (es decir, qué objeto estamos analizando), hemos de distinguir varios planos (o varios "objetos" de estudio):

(a) El plano texto: en donde únicamente podremos indagar sobre como las (infinitas, en principio) posibilidades de interpretación de una organización simbólica codificada y registrada se pueden ir reduciendo a relativamente pocas representaciones.

(b) El plano del discurso: en donde presentemos razones objetivas de por qué, entre las ya reducidas posibilidades de interpretación que aporta el texto, según el análisis de (a), escogemos la que hemos elegido.

(c) El plano del mensaje: en donde analicemos cuáles son los efectos que la representación que hemos elegido en (b) consigue sobre el resto de nuestras representaciones mentales y, si somos capaces, explicar el por qué. 
Alguien pensará: Para esto no hacían falta tantas palabras. Está claro que se trata de una cuestión simplemente terminológica. En realidad nos seguiremos ocupando de interpretaciones.

Es cierto. Pero ahora, el objeto de estudio son las interpretaciones personales, no el objeto "texto". Hemos pasado del análisis de objetos "terminados" físicamente presentes, al estudio de actividades en funcionamiento $\mathrm{y}$, por tanto, sin posibilidad de terminar más que en cada estudio de las mismas. Y esas actividades sí se pueden estudiar causalmente (científicamente). Es cuando no se tratan, cuando se dan por descontadas, cuando se interponen entre el investigador y lo que él cree que es la realidad. En una palabra, cuando no son objetivas.

\section{Bosquejo de análisis}

\section{6. (A) PLANO DeL TEXTO}

6. (A) (1) Características fisicas: se trata de un tarjetón escrito en alfabeto latino en un ordenador mediante el programa WPSI con letras del tipo CG Times $14 \mathrm{pt}$. En el medio, arriba, hay una sola palabra, amantes, en "negrita". El cuerpo del texto está compuesto por cuatro líneas, la primera de las cuales tiene once palabras (ortográficas. Es decir, tiras de letras separadas por espacios entre ellas. Hay un punto después de la sexta palabra); la segunda, nueve (una antes de un punto y ocho después de él); la tercera, doce (dos antes de una coma y las diez restantes finalizan con otra coma); la cuarta línea tiene cinco palabras Debajo del cuerpo del texto hay otra línea entre paréntesis con cinco palabras: las tres primeras empiezan con caracetres mayúsculos, le siguen dos puntos y a estos le siguen las dos últimas palabras, la primera de las cuales también se inicia con mayúscula, Ambas están escritas en cursiva. 


\section{6. (A) (2) características lingüísticas ${ }^{35}$}

Es un texto escrito en uno de los idiomas hispánicos: el castellano (que generalmente se conoce también como "español") reciente.

La primera palabra, amantes, es un sustantivo cuyo último elemento es la letra $s$ que representa el fonema [PLURAL] del idioma castellano. Está compuesto por la raiz morfológica $<\mathrm{AMA}(\mathrm{R})>$ y la terminación $<\mathrm{NTE}>$ indicadora del participio de presente de los verbos. Debido a estas caraterísticas, la palabra española amantes se decodificaria como "dos o más seres humanos que están realizando una acción (o que están en un estado activo) que tiene que ver con amar (atraerse sentimental y sexualmente)".

La primera oración del texto consta de dos cláusulas, una de las cuales depende de la otra. La claúsula principal es no pude creerlo que está negativamente modalizada (no pude) que viene a significar que hay una imposibilidad de realizar la acción mental que indica el verbo lexical (creer). La forma del verbo modal indica que esta oración está en primera persona, es decir que su sujeto gramatical es quien la está profiriendo (en este caso, quien la ha escrito). El objeto de la creencia se halla indeterminado en la oración (lo). La cláusula subordinada está conectada a la principal por el adverbial hasta que (formado por el adverbio hasta, un sustantivo implícito no determinado --.- que sirve de antecedente al relativo (que). Este relativo es la circunstancia de la oración les descubri, cuyo objeto directo/indirecto (les) es indeterminado pero refiriéndose a dos o más sustantivos uno de los cuales, al menos, es del género masculino ( $\mathrm{y}$ posiblemente "persona", si el autor no es "leista" en su idiolecto del castellano).

La segunda oración consta de una sola cláusula, en donde el sujeto es un sustantivo plural indeterminado referencialmente, muchos. El objeto indirecto es el pronombre singular me que se debe referir a la persona que profiere (aquí, que escribe) la oración. El objeto directo es el pronombre neutro singular, $l o$, indeterminado referencialmente. El grupo verbal está compuesto del auxiliar $[<$ HABER $>+<$ PASADOIMPERFECTO $>$ ]y el lexical [ $<$ DECIR $>+<$ PARTICIPIO PASIVO $>$ ] en la forma de tiempo gramatical pasado perfecto, cuya referencia es pasada $y$, por el momento, terminada.

La tercera y última oración consta de dos cláusulas principales (En aquel momento ella (-) dejó de maullaripero él (-) todavia siguió ladrando), unidas por una

Para no hacer màs largo este análisis no distinguiré entre aspectos fonológicos, morfosintácticos y semánticos sino que trataré algunos que me parezcan más relevantes, con lo que introduzco un elemento NO objetivo, sin analizar: lo que a mí me parece más relevante. Espero que, aunque esto sea cierto en este momento, se entienda el tipo de análisis que se podría realizar.

Pragmalinguistica, 5-6, 1997-1998, 173-209. 
conjunción adversativa (pero) que tienen, cada una, una subordinada: la primera es un inciso (asustada) resultante de una cláusula de relativo de la que ha sido eliminado el relativo y el verbo de estado; la segunda es una oración de relativo completa (que no se daba cuenta de (-)); esta última subordinada tiene otra subordinada de relativo (que les estaba mirando).

La primera cláusula principal comienza con un adverbial (en aquel momento) de referencia imprecisa, a la que sigue un pronombre determinado femenino singular de referencia imprecisa que es el sujeto (ella). El verbo de acción que sigue es un verbo compuesto de una raiz verbal $<\mathrm{DEJAR}>$ y de una partícula $<\mathrm{DE}>$ y está en el tiempo verbal pasado indefinido (dejó de) con referencia pasada e imperfectiva. El objeto de estos verbos es típicamente un verbo de acción en infinitivo (maullar) que se refiere a los sonidos que realizan los gatos. La cláusula incrustada (asustada) consta solamente de un participio de pasado que, unida a un verbo de estado que se ha evitado aqui, indica precisameente eso, un estado de ánimo de algo/alguien de referencia no determinada.

La cláusula principal de la cláusula que aparece detrás de la adversativa consta de un pronombre determinado singular masculino (por eso va gráficamente marcado con el acento) de referencia imprecisa (él) que es el sujeto del grupo verbal formado por el verbo propiamente dicho, en tiempo gramatical de pasado indefinido (siguó) y su objeto verbal en forma de gerundio (ladrando) a los que hay que añadir las circunstancias que determinan la duración de la acción y que están colocadas alrededor del verbo y su objeto (todavia (-) un rato). Aquí hay una pequeña trampa: la palabra todavía en la primera lectura apresurada puede ser circunstancia de la cláusula subordinada que no se daba cuenta de que les estaba mirando, $X$. Lo que ocurre es que al terminar dicha palabra no hay ninguna marca (o, en este caso, coma) por lo que se adscribe a la oración principal como he hecho yo en este análisis. La claúsula subordinada principal tiene como sujeto al relativo que al que hay que encontrar referente; la cláusula está marcada negativamente (no) y le sigue el grupo verbal formado por el reflexivo se (objeto indirecto), por el verbo en tiempo pasado imperfecto (referencia imperfectiva), daba, y su objeto directo (cuenta). Todo ello está lexicalizado en castellano formando un verbo específico [ $<\mathrm{DAR}>+<\mathrm{SE}>+<$ CUENTA $>$ ] cuyo objeto directo va precedido de la preposición de. En este caso, el objeto es otra oración subordinada de relativo con el relativo que como sujeto de referencia indeterminada, les como objeto plural (uno de cuyos miembros ha de ser masculino, en el idiolecto estándar del castellano) de referencia indeterminada y el elemento verbal se encuentra en forma progresiva de tiempo gramatical pasado y de referencia imperfectiva (estaba mirando).

Hemos hecho dos análisis textuales hasta ahora. ¿Estaría un profesor contento con

Pragmalinguistica, 5-6, 1997-1998, 173-209. 
ellos? Supongo que diría que el primero es un análisis de la materialidad del objeto en donde están registradas ciertas palabras; y que el segundo es un análisis fono-morfosintáctico-semántico ("gramatical", para resumir). Y eso NO es un análisis de texto. Sin embargo, a partir de ahora, ya no podemos seguir analizando el texto -lo que no cambiasino lo que interpretamos (a partir de lo que está físicamente presente ante nosotros, como objeto, y como organización codificada de palabras del español). Por lo que ya no vamos a analizar algo externo a nosotros, sino el proceso interno que sigue una de las mentes (la mía en este caso) que lo interpreta en un momento dado, y que, por tanto, cambiará con cada interpretación. Es decir, el primer nivel científico, el de saber qué observamos se ha clarificado: OBSERVAMOS un proceso mental $\mathrm{y}$, al analizar los resultados que obtiene en un determinado momento (en el que escribo estas líneas, por ejemplo), pensamos que se puede realizar una DESCRIPCIÓN adecuada del mismo ${ }^{36} \mathrm{e}$, incluso, una EXPLICACIÓN causal. Si es asi, llegaremos, por fin, a un enfoque teórico científico de este fenómeno comunicativo.

\section{6. (B) PLANO DEL DISCURSO:}

En todos los textos, generalmente, las palabras están colocadas en estructuras oracionales que, si no pertenecen al género poético, siguen unas a otras en líneas sólo separadas por puntos y aparte. Por tanto, la pimera palabra, amantes, al estar sola encima del resto del texto, funciona como título introductor del resto. El significado lingüístico de esta palabra sería aproximadamente el que ofrecí antes y que ahora repito: "Dos o más seres humanos que están realizando una acción (o que están en un estado activo) que tiene que ver con amar (atraerse sentimental y sexualmente)". El problema con este tipo de definición es que resulta dudosamente especificada por mi percepción de esta palabra en el contexto en que sé que me estoy moviendo. Considero muy dificil ofrecer una definición consciente de cualquier término de nuestro léxico en donde no haya entrado algún elemento propio de la interrelación de mi mente con el contexto ${ }^{37}$. Pero

in No de los resultados que ahora consigamos, sino del proceso en sí mismo, como algo en funcionamiento dinámico.

"En realidad, cada término lingúistico se refiere a un concepto primario interconexionado con gran cantidad de otros conceptos primarios. Es el contexto el que determina a menudo que tipos de conexiones se activan para aportar un significado complejo apropiado. Recuérdese, además, que, a pesar de que a veces se confunde con él, el contexto no es el entomo físico, sino un constructo mental en donde hay representaciones más o menos fertemente manifiestas (Cfr , Sperber \& Wilson, 1986).

Pragmalingüistica, 5-6, 1997-1998, 173-209. 
como moverse en el plano cognitivo (es decir, de "conocimiento" central post-modular (Cfr. Fodor, 1981)) resulta más simple en una exposición como ésta, lo seguiré haciendo así, por el momento.

En todo caso, al leer la palabra amantes, tengo acceso a algo parecido a la definición recién comentada y a algunos datos más que se hallan manifiestos en $\mathrm{mi}$ concepción del mundo. Por ejemplo, que los amantes no son generalmente parejas estables, y que, lo más seguro, es que vivan apasionadamente su amor a escondidas de alguien cercano que, por lo común, es el otro o la otra componente de la pareja estable, aunque puede ser también un pariente que no aprueba este tipo de relaciones (madre, padre $o$, incluso, tutores, etc.).

Todas estas representaciones funcionan automáticamente (por eso me refería en la nota anterior a que podrían activarse en paralelo) y me hacen interpretar estas dos cosas:

$\left(1^{\circ}\right)$ Que el que escribió esta palabra se estaba refíriendo a este tipo de amantes que acabo de dibujar

$\left(2^{\circ}\right)$ Que debido a que esta palabra es un título y que, en mi conocimiento del mundo, un título representa un resumen o "tematizador" de lo que sigue, lo que voy a leer a continuación va a tratar de amores apasionados y (de alguna manera) ilegales.

Empecemos con el análisis discursivo de la primera oración. Recuérdese que tenemos que convertir la oración, una vez decodificada, en una proposición con sentido. Esto significa que hay que (a) resolver las ambigüedades que hubiere, (b) asignar referencias no especificadas y (c) enriquecer conceptos cuando se requiera ${ }^{31}$. La primera ambigüedad es la del verbo pude que tiene valor realmente modal o modular ${ }^{39} \mathrm{y}$ hay que elegir. No parece que el valor modal sea relevante en este caso, sino que se está tratando de modularizar el proceso de creer y hacerlo casi imposible.

La referencia del lo no está clara en un primer momento. Sin embargo, si sigue muy presente en la mente el concepto de amantes que acabo de describir antes, es posible que alguno ya le asigne al lo la referencia a algo así como "la situación de amantes". En mi caso, sin embargo, el lo se quedó en suspenso, porque, a partir de mi

3* Cfr., Sperber \& Wilson (1986).

Z̃ Según la terminología de Halliday (1970).

Pragmalinguistica, 5-6, 1997-1998, 173-209 
experiencia, tengo la representación de que hay algunos pronombres que se refieren a elementos subsiguientes ${ }^{40}$.

La palabra hasta es también ambigua. O, mejor dicho, el sustantivo implícito no determinado al que rige es ambiguo. Podría ser, entre otros varios, "hasta EL MOMENTO" o "hasta EL LUGAR". Parece que el primer significado me resulta más relevante en este caso porque aporta efectos contextuales con menos procesamiento. En efecto, podría haber sido "hasta que LLEGUÉ AL LUGAR DONDE les descubri", de evidente mayor complejidad al "hasta EL MOMENTO que les descubri"4l que he elegido. Sólo habría escogido el primero si hubiera habido un enriquecimiento patente de efectos contextuales, si hubiese obtenido mayor información, lo cual no es el caso, al menos para mi en este momento de lectura ${ }^{42}$.

La asignación de referencia al pronombre les hace que señale a los "amantes". No está claro el funcionamiento de esta asignación.

-Es posible que se trate de una inferencia en el nivel cognitivo. En este caso tendríamos que tener como representación muy accesible la del título, amantes, con la serie de representaciones que aludí antes. Entonces la inferencia sería de este tipo: PREMISA $1^{2}$ : Hay unos amantes (que son personas que, por definición se esconden) $2^{a}$ PREMISA: Alguien descubre "les". CONCLUSIÓN: Luego este "les" se refiere a los que estaban escondidos: los amantes

- También se podría tratar de un procesamiento en paralelo subcognitivo, en cuyo caso no hay inferencia sino simplemente una puesta a punto de las relaciones del "les" con toda una serie de conceptos contextuales fuertemente activados.

No me pronunciaré todavía sobre uno u otro modelo, pero espero que los procedimientos mentales que estoy describiendo empiecen a ser percibidos, al menos, en su manera de funcionar.

1. PREGUNTA: esto, ¿es inferencia o es pura y simple deodificación de mi lengua? Trataré de este problema al final, aunque ya lo he apuntado al hablar de las conexiones sub-cognitivas en paralelo.

* Cfr Sperber \& Wilson (1986).

$\therefore$ Obsérvese, de pasada, que sı hubiera elegidoel primer sentido, el que habría dejado de ser relativo. No así en el segundo. Lo cual, de nuevo, plantea si esta elección es cognitiva o infracognitiva.

Pragmalunguística, 5-6, 1997-1998, 173-209 
Es posiblemente en este momento cuando asigno referencia al subsecuente del lo anterior. "Lo" que el escritor afirma es que "descubrió que existían amantes". Y como parace obvio que todos en nuestra cultura tenemos muy manifiesta la representación de que existen amantes, la proposición, para ser relevante, habría que enriquecerla con algo como "y al que escribió eso le importaba mucho la existencia de los amantes" que, enseguida, al ponerse en contacto con otras premsas, como que al que más le importa descubrir a los amantes es al miembro de la pareja del que se esconden, sacamos la conclusión de que el que escribe es precisamente ese miembro de la pareja.

Las conclusiones anteriores parecen corroborarse con la oración siguiente que enriquecemos discursivamente así:

En mi contexto mental hay representaciones (pasablemente manifiestas) de personas que se erigen en representantes del statu quo y que rápidamente cuentan al miembro de la pareja "oficial" que está siendo "engañado/a". Por tanto, la indeterminación referencial del sujeto muchos se realiza, en mi mente, asignándole referencialemte esa representación.

El lo objeto directo de advertir, se refiere a la misma representación que el lo que vimos, con to que ésta se refuerza. También se refuerza por uno de los sentidos de advertir que, en este contexto, se activa más que los demás. "Advertir es llamar la atención sobre algo desagradable para el que escucha".

La referencia del adverbial se realiza en una operación inferencial (cognitiva) o en una conexión paralela (subcognitiva) que se fija en "el momento en que los descubri" por razones que voy a dar por obvias para no tener que desarrollarlas de nuevo (vide supra).

Con la asignación referencial de ella conseguimos varias cosas: "Ella es el miembro de la pareja establecida que, además, es amante (de otra persona)". Por tanto, el que escribe es (como representación más manifiesta en mi mente) "un hombre" y el amante de ella es otro hombre. Estas son las representaciones más fuertemente manifiestas. El inciso, asustada, refuerza esta representación, puesto que una mujer cogida "en falta de amor" "en nuestra sociedad tiene miedo a las consecuencias" (otra representación manifiesta, quizá no tan fuertemente, en este contexto que acabo de describir).

Las representaciones eran tan fuertemente manifiestas en este punto para mi que interpreté "dejó de maullar" de la manera siguiente. PREMISA 1": En los actos sexuales (llamados de amor) los seres humanos emiten gemidos. PREMISA 2a: Algunas personas creen que el femenino es el sexo "débil", por lo que, de manera metafórica, a los gemidos, los sustituye por "maullidos" que es lo que hace un gato y no el león (que sería el sexo fuerte). CONCLUSIÓN: Ella interrumpió asustada su acto sexual con su amante. ¿Por qué? Otra inferencia: porque anteriormente él ha dicho que "los descubrió" y fue

Pragmalinguistica, 5-6, 1997-1998, 173-209 
en "ese momento". Etc.

Lo malo es que la última proposición ha roto el entramado de representaciones que se me habian hecho manifiestas y me ha hecho reconstruir toda la representación casi desde el principio. Es lo que se llama en inglés un efecto garden path y que yo he bautizado, con perdón, como una interpretación con marcha atrás.

La adversativa pero, sólo indica que lo que se diga a continuación tiene que procesarse como, en algún sentido, contrario a lo que se ha dicho hasta ahora. Al pronombre $e ́ l$, sin entrar en muchos de talles del proceso, parace claro que hay que asignarle la referencia más relevante en este caso: el otro miembro de la pareja de amantes (para mi todavía, "el rival" del que escribe). El predicado de la oración indica que, al revés que la amante, el "rival" no ha tenido conciencia del "peligro", con lo que se confirma la hipótesis de la adversativa que en este caso se trata de una información contradictoria a lo anterior.

Como indiqué antes, el adverbio todavia puede interpretarse como formando parte del sentido de esta proposición ("todavía no se daba cuenta"). Sin embargo, la coma que lo separa de ella nos hace integrarlo en la proposición siguiente. En este caso concreto creo que no se trata de un proceso inferencial, sino de uno propiamente decodificador, aunque éste sea un momento en donde los límites entre ambos no (ME) parecen claros.

Hasta este punto, todo lo que he ido interpretando sigue incidiendo en la representación mental que he adquirido a través de todo el proceso de lectura, fortaleciendo mis hipótesis sobre el tipo de información que el escritor quería que yo recuperase de su texto (aunque, para receptores más avisados que yo, quizá el maullido de ella podría haber sido una contra hipótesis que tendría que haber contrastado en su momento). La última oración, en cambio, cambia el valor de las hipótesis anteriores, de tal manera que las borra y crea otras nuevas de manera muy fuerte, con lo que el proceso interpretador sufre una sacudida.

La clave está en la palabra ladrando. En mi conocimiento del mundo o, si adoptamos el otro enfoque sub-cognitivo, en mi módulo lingüístico, el verbo "ladrar", al revés que el de "maullar" está bastante alejado de nociones de amor, gemidos, etc. En todo caso se conectaría con conceptos como "malos modos", "dar órdenes", etc. Está de hecho tan alejado del amor y sus gemidos, que actúa como premisa para la inferencia siguiente.

12 PREMISA: El amante ladra

$2^{\wedge}$ PREMISA: Sólo ladran los perros

CONCLUSIÓN: El amante es un perro

Pragmalinguistica, 5-6, 1997-1998, 173-209. 
Y a partir de ahi, y en cascada, toda una serie de nuevas inferencias que me permito no explicitar aquí de manera detallada, pero que llevarían, entre otras, a las siguientes representaciones muy manifiestas:

- El maullido de la amante no era metafórico, sino que era de una gata

- Es muy extraño que perro y gata, que son enemigos natos, se amen

- El que escribe no puede ser el amante de la gata (sino, posiblemente, su dueño)

- Por tanto no ha sido "engañado"

- Por tanto, la gente que se lo había dicho no lo había hecho con mala idea, sino con asombro

- Por lo que el no podía creerlo del texto no se refiere a su rabia de amante "engañado", sino al mismo asombro que tenía la gente.

Etc.

\section{6. (C) PLANo DEL MENSAJE:}

En este nivel es cuando se decide cuál es el, digamos, "valor" (otros le llaman "fuerza") que se le atribuye a la sucesión de proposiciones que acabamos de analizar en el discurso. Si se trata de un aserto, de una orden, o, como en este caso, de una narración, y si hay que seguir refinando, como por ejemplo, ahora. considerando que se trata de una narración "natural", "literaria", etc.

Es sabido que la teoría de los actos lingüísticos establece que hay unas condiciones de éxito que son las que consiguen que un determinado acto sea o no lo que pretende ser. Parece desprenderse de algunos de los modelos de dicha teoría que se trata de una serie de normas sociales de intercambio que deben ser manifiestas en la mente de los comunicantes.

De esta manera, también requieren ser comunicadas, ya sea lingüísticamente, ya sea de manera inferencial, con arreglo a datos del contexto y los que se desprenden del propio discurso. S\&W las llaman explicaturas (las que se hacen manifiestas lingüisticamente)/implicaturas (las que se hacen manifiestas de manera inferencial) de segundo nivel.

Es decir, sabemos muy bien qué es una narración y qué es una orden. Pratt (1977) ha caracterizado la narración en general como la que cumple con las condiciones de "despliegue" y la adjunta de "elaboratividad".

Utilizando la idea de $\mathrm{S} \& \mathrm{~W}$ de distinguir entre la utilización normal de la información interpretada a partir de la recreación de un discurso, y la mención de esa 
información como un todo con el fin de adoptar una actitud manifiesta ante ella, pensé que, al menos la condición de despliegue propuesta por Pratt, podría interpretarse como una indicación "explicada" lingüísticamente o "implicada" contextualmente de cómo PROCESAR la información. Según Pratt, sería recreando la información discursiva y anadiendo información evaluativa sobre la primera. En este sentido parece muy similar al tipo de procesamiento "en eco" de la ironía, tal y como lo plantean $\mathrm{S} \& \mathrm{~W}$, en donde el locutor expresa su actitud (de no compromiso) ante el mensaje que emite y que, como es natural, pretende que sea (si no siempre "mutuamente" manifiesta, al menos "posiblemente" manifiesta) en la comunicación.

El otro rasgo, la "elaboratividad", propuesta por Pratt, no sería más que una de las maneras de indicar implicativamente que el texto requiere más esfuerzo interpretador, compensado por mayores efectos contextuales, si se procesa.

Por su parte. Zwaan (1993) postula la existencia de un esquema de interpretación que proyecta el tipo de operaciones que cada uno hará en la comunicación de determinados mensajes (el autor distingue en su artículo entre la narración de noticias y la narración literaria). Todas estas ideas, más o menos apuntan al mismo problema. Existe una evidente posibilidad de cambiar el modo de procesar la información que se intenta compartir en la comunicación.

De todas maneras, aunque la idea intuitiva está básicamente clara, tengo mis dudas sobre la entidad cognitiva de estas "condiciones". ¿Se trata de verdaderas representaciones, como parece desprenderse de los autores citados (Zwaan lo afirma categóricamente)? ¿O se trata simplemente de conexiones que se activan ante determinados estímulos? Quizá sea demasiado potente la idea expresamente defendida por Zwaan de que tenemos representaciones mentales de los tipos de texto que nos llegan en un discurso, aunque no sería extraño, en principio, que algunas de las características que propone sobre nuestro funcionamiento interpretativo sean plausibles y hasta demostrables. Pero, ¿probaria esto que tenemos esas representaciones SIEMPRE en nuestra memoria de largo plazo como pretende indicar? Otra manera de explicar este funcionamiento de manera también aceptable sería, me parece, postular que cuando se producen una serie de conexiones en paralelo (de elementos de la memoria a corto y largo plazo, de elementos del entorno, de elementos aleatorios, incluso, etc.) se crean SOBRE LA MARCHA posibilidades de funcionamiento semejantes que, posteriormente, en un nivel ya cognitivo, se pueden asociar a representaciones tales como "literario", "noticias", etc. Es decir, aunque postulemos que muchas de las representaciones de la lengua humana sigan siendo más o menos estables (ideas, reglas, etc.), no todos los modos de funcionar han de estar predeterminados por representaciones ya elaboradas, sino que podrían irse formando a medida que se procesaran. 
Supongamos que la historia que hemos analizado nos la contara nuestro vecino del quinto, no apareciera en un recuadro, firmada y con título, etc. Nunca la asociariamos con algo literario que, además, no sabemos definir mediante condiciones suficientes y necesarias (lo cual no implica que no esté representado en nuestra mente, por supuesto). ¿No parece más lógico afirmar que la procesaremos de manera distinta según se pongan en marcha unas conexiones y no otras? ¿Por qué va a tener que existir un esquema de interpretación literaria distinto del de interpretación de noticias como pretende Zwaan? ¿Por qué no admitir que según los distintos mapas de conexiones que se establezcan en un momento dado el funcionamiento interpretativo será diferente? Esto es lo que, por su parte, aunque en distinto campo, parece que quiere postular Gibbs (1994), después de realizar varios experimentos de creación de conceptos.

No estoy afirmando nada con seguridad. Estoy planteando una duda que por el momento no sé resolver. Quizá la podríamos intentar integrar con la cognitiva, tal y como lo hace Bechtel (1990), admitiendo que en los procesos interpretativos y, en general, en los procesos mentales, hay efectos que se explicarian mejor de manera conexionista sub-cognitiva y otros, en cambio, que requieren una explicación cognitiva. En todo caso, a la hora de indicar que algo es (o no) "literario", hemos de poseer al menos una noción (o representación estable) de qué es esa literariedad. Lo cual no nos prohibe pensar que ANTES, si el discurso no es claramente marcado como literario (no está en un libro, tiene un autor, ha sido objeto de crítica, nos lo han recomendado, etc.), se interprete como tal (o no) porque se activan algunas conexiones en detrimento de otras y son éstas las que inducen a procesar la información de una u otra manera.

La cuestión se halla, por el momento, y a pesar de los argumentos de Zwaan, abierta para mí. Lo que me gustaría es alentar a que nos empecemos a plantear este tipo de problemas que son los que, con ciertas posibilidades de resolverse por medio del pensamiento terciario, nos permitan entrar de lleno en el mundo de la ciencia de manera clara. Por ejemplo, al densificar las posibles conexiones de rasgos conceptuales, se puede seguir un modelo matemático contínuo. Este tipo de matemática contínua tiene actualmente un problema en su aplicación a la física: no está muy claro que existan realmente espacios contínuos en lo que se refiere a las entidades físicas. En cambio, al parecer, sus propiedades, hasta ahora meramente especulativas y sin aparente validez empírica, podría concretarse en aspectos semánticos (mentales y/o lingüísticos) cuya naturaleza parece corresponder a dichas propiedades de los contínuos.

Pragmalinguistica, 5-6, 1997-1998, 173-209. 


\section{Referencias}

BAXANDALL, M. (1985), Modelos de Intención, (traducción española) Hermann Blume.

BECHTEL, W. (1990), "Connectionism and the Philosophy of mind: An overview", en Lycan (ed).

BODEN, M. (1990), The Creative Mind, Abacus, 1994.

BOYER, P. (1990), Tradition as Truth and Communication. A Cognitive Description of Traditional Culture, Cambridge University Press.

BROWN, G. \& YULE, G. (1983), Discourse Analysis, Cambridge University Press.

CASTILLA DEL PINO, C. (1988), "Tipología de los discursos y su utilización en psico(pato)logia", R.A.E.N., Vol. III, no25, pgs. 181-194.

CLARK, A. (1989), Microcognition. Philosophy, Cognitive Science, and Paralell Distributed Processing, second printing, 1990, Bradford Books, MIT Press.

DENNETT, D. (1978): Brainstorms: Philosophic Essays on Mind and Psychology, Bradford Books, MIT Press.

FODOR, J.A. (1983), The Modularity of Mind, MIT Press.

FODOR, J.A. (1985), "Précis of the modularity of the mind", en Fodor (1990).

FODOR, J.A. (1990), A Theory of Content and other Essays, MIT Press.

GIBBS, R.W. (1994), The Poetics of Mind: Figurative Thought, Language and Understanding, Cambridge University Press .

GROSS, S. (1997), "The word turned image: reading pattern poems", Poetics Today $18: 1,15-32$.

GUIJARRO MORALES, J.L. (1994), "Giro copernicano en los estudios humanísticos", Pragmalinguistica 2.

HALLIDAY, M.A.K.(1970), "Functional diversity in language, as seen from a consideration of modality and mood in English", reeditado en Krees (ed.)(1978).

HOLLIS, M. \& LUKES, S. (1982), Rationality and Relativism. Basil Blackwell.

HORTON, R. (1967), "African traditional thought and modern science", Africa, n.38, en Wilson (ed.)(1970).

HORTON, R. (1982), "Tradition and modernity revisited", en Hollis \& Lukes (eds).

KUHN, T. S.(1970), The Structure of Scientific Revolutions (2nd edition) University of Chicago Press.

KREES, (ed.) (1978), Explorations in the Functions of Language, Amold.

LYCAN, W.G. (1990), Mind and Cognition, Basil Blackwell.

MARR, D. (1982), Vision, W.H. Freeman \& Co.

MEHRABIAN, A. (1972), Nonverbal Communication, Aldine, Atherton. 
PAPINEAU, D. (1987), Reality and Representation, Basil Blackwell, 1991.

POYATOS, F. (1994), La comunicación no verbal, (3 volúmenes), Biblioteca Española de Lingüística y Filología, Itsmo.

PRATT, M.L. (1977), Towards a Speech Act Theory of Literary Discourse, Indiana University Press.

PYLYSHYN, Z. (1986), Computation and Cognition, MIT Press.

RIVIERE, A. (1986), Razonamiento y representación, Siglo XXI.

RIVIERE, A. (1991), Objetos con mente, Alianza Editorial, Psicología Minor

SCARRY, E. (1995), "On vivacity: the difference between daydreaming and imaginingunder-authorial-instruction", Representations, 52, 1-26.

SPERBER, D., CARA, F. \& GIROTTO, V. (1994), "Relevance Theory explains the selection tasks", Cognition, 57 (1995), 31-95.

SPERBER, D. \& WILSON, D. (1986), Relevance. Communication and Cognition, Blackwell (trad. francesa en Editions de Minuit (1989) y nueva edición corregida y aumentada en Blackwell (1995).

VEGA, M. de (1984), Introducción a la psicologia cognitiva, Alianza, Psicología, 1993. WILSON, B. (ed.)(1970), Rationality, Basil Blackwell.

ZWAAN (1993), Aspects of Literary Comprehension, John Benjamins Publishing Company. 